- 71 UASC from the same borough were seen for ID screening, resulting in a diagnosis and treatment in $42 \%$ (including hepatitis B, schistosomiasis and latent tuberculosis).

- 51 UASC from the same borough had appointments at a local sexual health service of whom 11/51 (22\%) did not attend; the remainder received sexual health screening and education.

Conclusion An integrated pathway for UASC has been successfully implemented in a London borough and supports practitioners from across the field to understand and address UASC health needs. This approach requires further evaluation but has resulted in high rates of referral and engagement with appropriate services, and identification of health needs. Future plans include co-location of services, a dedicated interpreting service, collection of service user feedback and long-term outcomes.

\section{G167 IMPROVING OUTCOMES FOR YOUNG CHLDREN IN REFUGEE FAMILIES: LESSONS FROM SOMALI PARENTS' EXPERIENCES OF PLAY AND SOCIAL INTERACTION IN THE UK}

1,2TD Allport, '1 Mace, ${ }^{2} \mathrm{~F}$ Farah, ${ }^{2} \mathrm{~F}$ Yusuf, ${ }^{3} \mathrm{~L}$ Mahdjoubi, ${ }^{4} \mathrm{~S}$ Redwood, ${ }^{1} \mathrm{Centre}$ for Academic Child Health, University of Bristol, Bristol, UK; ${ }^{2}$ Community Children's Health Partnership, Sirona CIC, Bristol, UK; ${ }^{3}$ Department of the Built Environment, University of the West of England, Bristol, UK; ${ }^{4}$ NIHR Applied Research Collaboration, National Institute of Health Research (NIHR), Bristol, UK

\subsection{6/archdischild-2020-rcpch.138}

Aims Adverse early child development and ill health risks poorer wellbeing, unemployment and criminal behaviour in later life. The children of disadvantaged migrants are at risk of delayed and disordered early development, with multiple factors potentially contributing to poor long term educational and social outcomes. Somali people are one of the world's largest diasporas, following forced migration from conflict; in Bristol, Somali children are $5 \%$ of the child population - they have high attendance rates at Emergency Departments, do less well at school and are more often referred for help with developmental difficulties, including six times higher rates of referral for the possibility of autism. We explored psychosocial contexts for these challenges.

Methods We asked six Somali mothers in Bristol about experiences of early childhood (both their own and subsequent observations) in Somalia and the UK, and of factors facilitating or restricting children's early opportunities for play, social interaction and development. Qualitative semi-structured interviews were analysed using an interpretative phenomenological approach.

Results In Somalia, mothers described a supportive, connected community and safe environment enabling children to play and learn together.

In the UK, by contrast, multiple local stressors affected family wellbeing and social networks, and constrained children's opportunities to play and interact, which may limit children's opportunities for early play and social experiences and influence health decision-making.

We have developed an Ecocultural model of challenges to young migrant children's development, integrating epigenetics, psycho-social and cultural factors.

We describe policy recommendations - to tailor statutory early childhood interventions for disadvantaged migrant communities, and for improvements to local environments for play and social interaction.

We report case studies involving alignment of existing services, employing community link workers, hospital-community and statutory-voluntary sector collaborations, and Community Infrastructure Levy funding.

Conclusion Our findings show how disadvantage can impair early child development and health in migrant families. Social isolation and lack of safe places to play are key points to address.

Building resilience, social networks and child-friendly communities in children's early years is likely to be most effective (and cost-effective) for improving young migrants' outcomes.

\section{G168 HPV: NOT JUST FOR GIRLS! A QUALITATIVE STUDY EXPLORING THE VIEWS OF 11-12 YEAR OLDS ABOUT THE HUMAN PAPILLOMAVIRUS (HPV) VACCINATION}

${ }^{1} \mathrm{E}$ Williamson, ${ }^{2} \mathrm{~A}$ Forster, ${ }^{1} \mathrm{H}$ Bedford. ${ }^{1}$ Population, Policy and Practice, UCL Great Ormond Street Institute of Child Health, London, UK; ${ }^{2}$ Research Department of Behavioural Sciences and Health, UCL, London, UK

\subsection{6/archdischild-2020-rcpch.139}

Background Since 2008, human papillomavirus vaccine (HPV) has been offered to $12-13$ year old girls in the UK to prevent infection that can lead to cervical cancer. Vaccine uptake in this schools based programme is generally very high. From September 2019, boys will also be offered the vaccine to reduce the burden of HPV-related disease in men. Little is known about boys' knowledge of HPV infection and attitudes towards the vaccine. This study aimed to explore 11-12 year old girls' and boys' understanding of HPV infection and their views about the vaccine. To assess their information requirements, their views of the content and appearance of draft HPV leaflets developed by Public Health England were also sought.

Methods Using a qualitative approach, four single-sex focus group discussions were conducted in two secondary schools. Discussions were audio recorded and transcribed using a thematic approach.

Results and Conclusions Thirteen girls and twelve boys took part in four focus groups. Emerging themes included vaccine views, knowledge and awareness of HPV infection, HPV vaccination programme knowledge and acceptability, receiving information about HPV and HPV vaccination. Awareness and knowledge of HPV infection and vaccination was low among all participants. Acceptability of HPV vaccination was high, especially after participants' questions and concerns were addressed through explanations. There was unanimous desire for accessible information before being offered the vaccine, using a combination of leaflets and face-to-face education from professionals, to enable participants to make an informed decision about vaccination. Participants primarily wanted information about the benefits of vaccination and potential adverse effects. The findings of this study highlight important areas that should be addressed by HPV information materials directed towards adolescents. Future research could evaluate the influence of different educational interventions in UK schools on knowledge and acceptability of the HPV vaccine. 